\title{
Do patients correctly use steroid nose spray? A patient-reported survey of the nasal spray technique and patient compliance
}

\author{
Waqas Jamil ${ }^{1}$, Abdullah Alahwal ${ }^{2}$, Ravinder Suman², Farah Naz ${ }^{3}$, and Thomas Beech ${ }^{1}$ \\ ${ }^{1}$ Queen Elizabeth Hospital Birmingham \\ ${ }^{2}$ Queen Elizabeth Hospital \\ ${ }^{3}$ Dow University of Health Sciences
}

September 11, 2020

\begin{abstract}
Objectives; To investigate spray technique and compliance among patients using steroid nasal spray. Design: Patient-reported survey Setting; Single centre study- a tertiary care hospital Participants: 100 participants (1 excluded) Main outcome measures 1) Nasal spray technique 2) Patient compliance Results: Out of 99 participants included in this study only one patient used steroid nose spray with a completely correct spray technique. Only $40 \%$ of patients received guidance instructions from the prescriber about the spray technique. $70 \%$ of patients reported using their spray regularly while $14 \%$ and $16 \%$ reported using mostly and sometimes respectively. $53 \%$ of patients were found using the correct dosage of the spray while $34 \%$ of patients were using incorrect dose and $13 \%$ cases dosage was unknown. Conclusions: Wrong spray technique is extremely common and can be easily corrected. Patient compliance can also be improved further. This survey emphasizes the importance of giving written and verbal instructions about the use of spray to the patients. We recommend following the written instructions for the use of steroid nasal spray from "British Society for Allergy and Clinical Immunology" or/and video tutorial from "asthma.org.ukhow to use nasal spray"
\end{abstract}

\section{Key Points:}

- Only 1 patient out of 99, used steroid nasal spray with a completely correct spray technique.

- Nasal spray technique was taught only to $40 \%$ of the patients

- $70 \%$ of the patients reported regular use of the steroid nose spray and $53 \%$ of patients were found to use correct spray dosage.

- Wrong spray technique and non-compliance can be the reason behind the treatment failure with steroid nasal spray.

- We recommend following "British Society for Allergy and Clinical Immunology-how to apply a nasal spray" and/or video instruction from "asthma.org.uk- how to use nasal spray" for the correct spray technique.

\section{Introduction:}

Background: Various studies have proven the efficacy of steroid nasal spray in the treatment of inflammatory nasal conditions ${ }^{1,2}$. Currently, topical steroid nasal sprays are considered as the first-line treatment for the management of allergic rhinitis (hay fever) and chronic rhinosinusitis ${ }^{1,3,4,5}$. Intranasal steroids work locally inside the nose and are found to be more effective than systemic steroids ${ }^{2}$. Local application of steroids in the nose reduces systemic absorption, hence reducing systemic side effects ${ }^{6}$. Various steroid-based nasal sprays are available i.e. Beconase, Nasonex, Avamys, Flixonase ${ }^{7}$. Combination nasal spray is also available which contains topical antihistamine and topical steroid i.e. Dymista ${ }^{8}$. 
Previous studies have investigated the correlation between spray technique and the distribution of drug inside the nose $e^{9,10,11,12}$. Correct spray technique and patient compliance are important factors for the nasal spray to work. Furthermore, incorrect spray technique can be associated with side effects i.e. irritation and epistaxis ${ }^{6}$. Current guidance on the management of chronic rhinosinusitis, allergic and non-allergic rhinitis strongly recommends clinicians to check nasal spray technique and compliance ${ }^{3,5}$.

Significant material is available on the internet for the patients on how to use the nasal spray but some of them are not as accurate ${ }^{7,13,14,15,16}$. Therefore, we recommend following the written instructions for the use of steroid nasal spray from "British Society for Allergy and Clinical Immunology" or/and video tutorial from " asthma.org.uk- how to use nasal spray" 7,13 (See below). We recommend following these steps when using steroid nose spray:

1. Clear the nose.

2. Slightly bend head forward.

3. Use opposite hand when holding spray (Right hand for left nostril and left hand for right nostril).

4. Direct spray inside the nose away from nasal septum (towards turbinate) towards ipsilateral ear or eye.

5. Administer spray- avoid hard sniffing.

6. Repeat the same for the other nostril.

Objectives: The main aims of this survey were:

1. To investigate if patients use a correct spray technique while administering steroid nose spray.

2. To investigate the patient's compliance in using the steroid nose spray.

\section{Materials and methods:}

Study design and Setting: This survey was conducted at Queen Elizabeth Hospital in Birmingham, UK. Initially, a written paper survey form (see figure 1) was distributed among the patients who were using steroid nasal spray and who came to attend rhinology and immunology outpatient clinics. But, shortly after this survey started, face to face patient consultations were stopped due to COVID-19 outbreak. Hence, a telephonic patient-reported survey was undertaken for the remaining patients. During the telephonic survey, we made a minor change in the question 3 of the survey (see figure 1) i.e. patients were asked to describe the head position, as patients can't see head position photos printed on the written survey form. Also, we educated patients about the correct spray technique while collecting answers for the telephonic survey.

Participants : As this survey was specifically about the use of steroid nose spray, non-steroid formulations were not included i.e. nasal decongestant spray, saline spray etc. Additionally, there is a minor difference in the way the steroid nasal drops are instilled in the nose as compared to the spray technique. This survey only included patients using steroid nose spray, not nasal drops.

\section{Data sources:}

Data collection started on 10 February 2020 and finished on 14 August 2020. We have chosen random patients from ENT rhinology and immunology clinics. During Pre-COVID phase of this survey, patients who came to attend clinic were verbally asked if they are using steroid nose spray and if they want to be a part of the survey. If the answer to both the questions was "yes" then the survey responses were recorded from those patients. Similarly, during COVID-19 outbreak, patients booked into the clinic who were using steroid nose spray were contacted by phone and if they agreed to be a part of this survey then their responses were recorded.

Study size : Data was collected from 100 patients.

\section{Results and analysis:}

Participants: Total100 patients took part in this survey. 15 patients filled in paper survey proforma before COVID-19 outbreak and the remaining 85 responded to the telephonic survey. Mean age of the participated 
patients in this survey was 49 years old, ranging from 18 to 77 years. There were 53 males and 46 females and the male: female ratio was 1.15:1.

When analysing patient's response, one respondent was using otrovine instead of steroid spray. Hence, we excluded this patient from the study, which dropped the total number of participants included in the study to 99 .

Patient responses: Patient responses to the survey questions are as below:

Who prescribed this nose spray?

1. ENT $53 \%$ (53 patients).

2. GP $42 \%$ (42 patients).

3. Over the counter $3 \%$ (3 patients).

4. $1 \%$ (1 patient) cannot remember who prescribed the spray

None of the spray was prescribed by the immunologist.

Were you shown how to use nose spray?

1. $40 \%$ (40 patients) responded yes

2. $60 \%$ (59 patients) responded No

Further breakdown of the taught spray technique in those $40 \%$ cases was:

1. $24 \%$ of cases (24 patients) by the ENT team.

2. $15 \%$ of cases (15 patients) by GP.

3. $1 \%$ of cases (1 case) by an asthma nurse.

Outcome Data:

Spray technique : Majority of the patients were using steroid nose spray with an incorrect spray technique. Only 1 patient out of 99 used steroid nose spray in a completely correct manner i.e. followed each step correctly. Different steps in using nose spray were all analysed separately i.e. head position, the direction of spray inside the nose, hand preference for holding spray bottle, sniffing, tasting spray in mouth (See figure $2)$.

Patient compliance : Compliance issues were also identified in the use of steroid nose spray. Majority of the patients revealed "regular" use of the spray $70 \%$ (69 patients). However, some patients reported using their spray "most of the times" 14\% (14 patients) and "sometimes" 16\% (16 patients) respectively. $53 \%$ of patients were found using correct spray dose but 34\% (34 patients) were using the incorrect dose of the prescribed spray; either underdosing or overdosing. 13\% (13 patients) were unable to recall the spray name, neither we were able to find the spray name in our documentation. Hence, we can not comment whether they used correct spray dosage (See figure 3).

Nasal sprays : Below is the list of nasal sprays and the percentage of patients using these sprays:

1. Dymista 33 patients (34\%)

2. Nasonex 21 patients $(21 \%)$

3. Avamys 23 patients $(23 \%)$

4. Flixonase 4 patients $(4 \%)$

5. Beconase 4 patients $(4 \%)$

6. Budenasoide 1 patient (1\%)

7. 13 patients cannot remember the name of the spray (13\%).

\section{Discussion:}

Key findings and interpretation: To our best knowledge, this is the first patient-reported survey assessing each step of the nasal spray technique and identifying the common mistakes. Out of 99 patients, only 1 
patient used the steroid nose spray with a completely correct spray technique. This survey also identified non-compliance in the use of steroid nose spray and using the wrong spray dosage. This is a major finding because we know that the spray technique and correct dosage are the two key factors for the success of medical treatment ${ }^{3,5}$. European position paper on chronic rhinosinusitis 2020 and British Society for Allergy and Clinical Immunology 2017 update on the management of Allergic and Non-Allergic rhinitis both emphasizes clinicians to check steroid nasal spray technique and patient compliance especially in cases of failed medical treatment ${ }^{3,5}$.

This survey also identified that spray technique was only taught in only $40 \%$ of cases when it should have been taught to every patient ${ }^{3,5}$. To complicate things further some of the material available on the internet for the patients about the spray technique is not reliable and accurate ${ }^{15,17}$. Some of the mistakes we found on reviewing this online material are mentioned below:

1. No mention of using contralateral hand ${ }^{15,17}$

2. No mention of directing spray towards turbinates ${ }^{15,17}$.

3. Breath in deeply as you squeeze the bottle. Remove the bottle and sniff once or twice ${ }^{15}$.

Turbinate bones in the nose are covered with soft tissue. Directing spray towards the turbinates will allow the medication to work locally on this soft tissue and maximise benefit and at the same time, it will prevent any side effects i.e. nose bleed, irritation ${ }^{6}$ associated with the application of the spray on the nasal septum. Hard sniff while administering the spray in the nose can force the drug to go into the oropharynx instead of working locally in the nose.

Comparison with already published literature: Compliance issues identified in the study were associated with both wrong spray dosage and not using the spray regularly. Non-compliance in the use of the nasal spray is a known factor which has been highlighted in the previously published literature ${ }^{6,18}$. Non- compliance rate found in our study was about 30\%. Ganesh et al. reported non-compliance in the nasal spray use in about $29.1 \%$ of patients. Similarly, Nabi et al. investigated the use of steroid nose spray in the patients after sinus surgery and reported non-compliance in $57.4 \%$ of patients.

Asthma control and its correlation with inhaler technique and patient compliance is a well-known association and a plethora of published literature is available ${ }^{19,20,21}$. Unfortunately, less literature is available about the nasal spray technique.

Strengths and limitations of this study and directions for future research:

This survey was an initial effort towards assessing steroid nasal spray technique and patient compliance in the use of nose spray. Firstly, despite our best effort to make survey questions clear and straightforward, it is still possible that some patients may not have understood the survey questions fully. Furthermore, this was a single centre study dealing with a small sample of the population in our hospital, hence results of this survey cannot be completely generalised but still, this study gives an insight to the clinicians on how prevalent wrong nasal spray technique can be among patients. We recommend for future to design a large-scale multicentre study to assess the spray technique in patients and to investigate the association between disease control and its correlation with nasal spray technique and compliance.

\section{Conclusion:}

Wrong spray technique is extremely common among patients using the steroid nose spray. This is something which currently seems to be overlooked by many clinicians, which is easily correctable. Moreover, patient compliance can be further improved. We emphasize the importance of giving verbal as well as written instructions to the patients when prescribing steroid nose spray.

Conflicts of Interest : None declared

Data availability statement: The data that support the findings of this study are available from the corresponding author upon reasonable request. 
Funding: No funding.

References:

1. Penagos M, Compalati E, Tarantini F, Baena-Cagnani C, Passalacqua G, Canonica GW. Efficacy of mometasone furoate nasal spray in the treatment of allergic rhinitis. Meta-analysis of randomized, double-blind, placebo-controlled, clinical trials. Allergy 2008 10/01; 2020/08;63(10):1280-1291.

2. Rodrigo G, Neffen H. Efficacy of fluticasone furoate nasal spray vs. placebo for the treatment of ocular and nasal symptoms of allergic rhinitis: a systematic review. Clinical \& Experimental Allergy 2011;41(2):160-170.

3. Fokkens WJ, Lund VJ, Hopkins C, Hellings PW, Kern R, Reitsma S, et al. European position paper on rhinosinusitis and nasal polyps 2020. Rhinology 2020;58(Supplement 29):1-464.

4. Allergic Rhinitis. 2018; Available at: https://cks.nice.org.uk/topics/allergic-rhinitis/. Accessed 08/01, 2020 .

5. Scadding GK, Kariyawasam HH, Scadding G, Mirakian R, Buckley RJ, Dixon T, et al. BSACI guideline for the diagnosis and management of allergic and non-allergic rhinitis (Revised Edition 2017; 2007). Clinical \& Experimental Allergy 2017;47(7):856-889.

6. Ganesh V, Banigo A, McMurran A, Shakeel M, Ram B. Does intranasal steroid spray technique affect side effects and compliance? Results of a patient survey. The Journal of Laryngology \& Otology 2017;131(11):991-996.

7. Topical Nasal Corticosteroid Spray. 2017; Available at: https://www.bsaci.org/wpcontent/uploads/2019/12/Howtouseanasalspray.pdf. Accessed 08/01, 2020.

8. Dymista. 2020; Available at: https://www.dymista.co.uk/en-gb/dymista-allergy-nasal-spray. Accessed 08/01, 2020.

9. Merkus P, Ebbens FA, Muller B, Fokkens WJ. The 'best method' of topical nasal drug delivery: comparison of seven techniques. Rhinology 2006 Jun;44(2):102-107.

10. Bateman N, Whymark A, Clifton N, Woolford T. A study of intranasal distribution of azelastine hydrochloride aqueous nasal spray with different spray techniques. Clinical Otolaryngology \& Allied Sciences 2002;27(5):327-330.

11. Tsikoudas A, Homer J. The delivery of topical nasal sprays and drops to the middle meatus: a semiquantitative analysis. Clinical Otolaryngology \& Allied Sciences 2001;26(4):294-297.

12. Aggarwal R, Cardozo A, Homer J. The assessment of topical nasal drug distribution. Clinical Otolaryngology \& Allied Sciences 2004;29(3):201-205.

13. How to use nasal spray. 2020; Available at: https://www.asthma.org.uk/advice/inhaler-videos/nasalspray/. Accessed 08/01, 2020.

14. Nasal Sprays: How to Use Them Correctly. 2000; Available at: https://www.aafp.org/afp/2000/1215/p2695.html. Accessed 08/01, 2020.

15. Nasal Sprays: How to Use Them Correctly. 2017; Available at: https://familydoctor.org/nasal-sprayshow-to-use-them-correctly/. Accessed 08/01, 2020.

16. HOW TO GET COMFORTABLE WITH NASAL SPRAYS (YOUR NOSE WILL THANK YOU!). 2018; Available at: https://www.flonase.com/allergies/how-to-use-nasal-spray/. Accessed 08/01, 2020.

17. Nasal Sprays: How to Use Them Correctly. 2017; Available at: https://familydoctor.org/nasal-sprayshow-to-use-them-correctly/. Accessed 08/01, 2020.

18. Nabi S, Rotenberg BW, Vukin I, Payton K, Bureau Y. Nasal Spray Adherence after Sinus Surgery: Problems and Predictors. Journal of Otolaryngology-Head \& Neck Surgery 2012;41.

19. Baddar S, Jayakrishnan B, Al-Rawas OA. Asthma control: importance of compliance and inhaler technique assessments. Journal of asthma 2014;51(4):429-434.

20. Hamdan A, Ahmed A, Abdullah A, Khan M, Baharoon S, Salih SB, et al. Improper inhaler technique is associated with poor asthma control and frequent emergency department visits. Allergy, asthma \& clinical immunology 2013;9(1):8.

21. Kebede B, Mamo G, Molla A. Association of Asthma Control and Metered-Dose Inhaler Use Technique among Adult Asthmatic Patients Attending Outpatient Clinic, in Resource-Limited Country: A 
Prospective Study. Canadian respiratory journal 2019;2019.

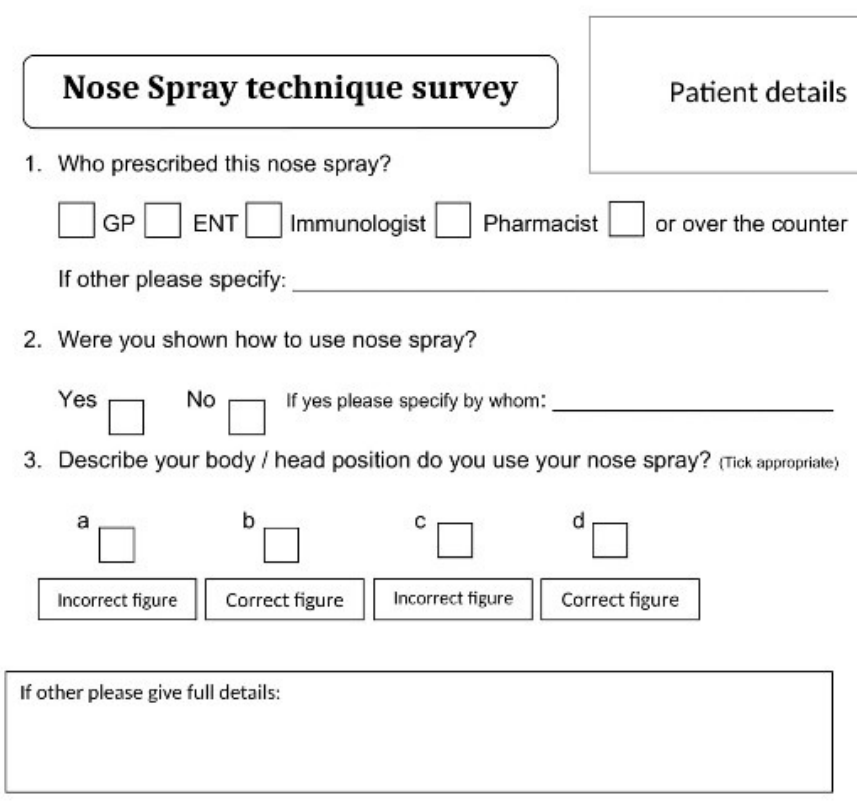

4. In which direction in the nose you squirt your nose spray?
a.
Towards middle (middle partition- septum) of nose
b. Away from middle (septum), towards side of nose.
c. Don't think about it.

Give full details:

$\mathrm{PTO} \rightarrow$ 

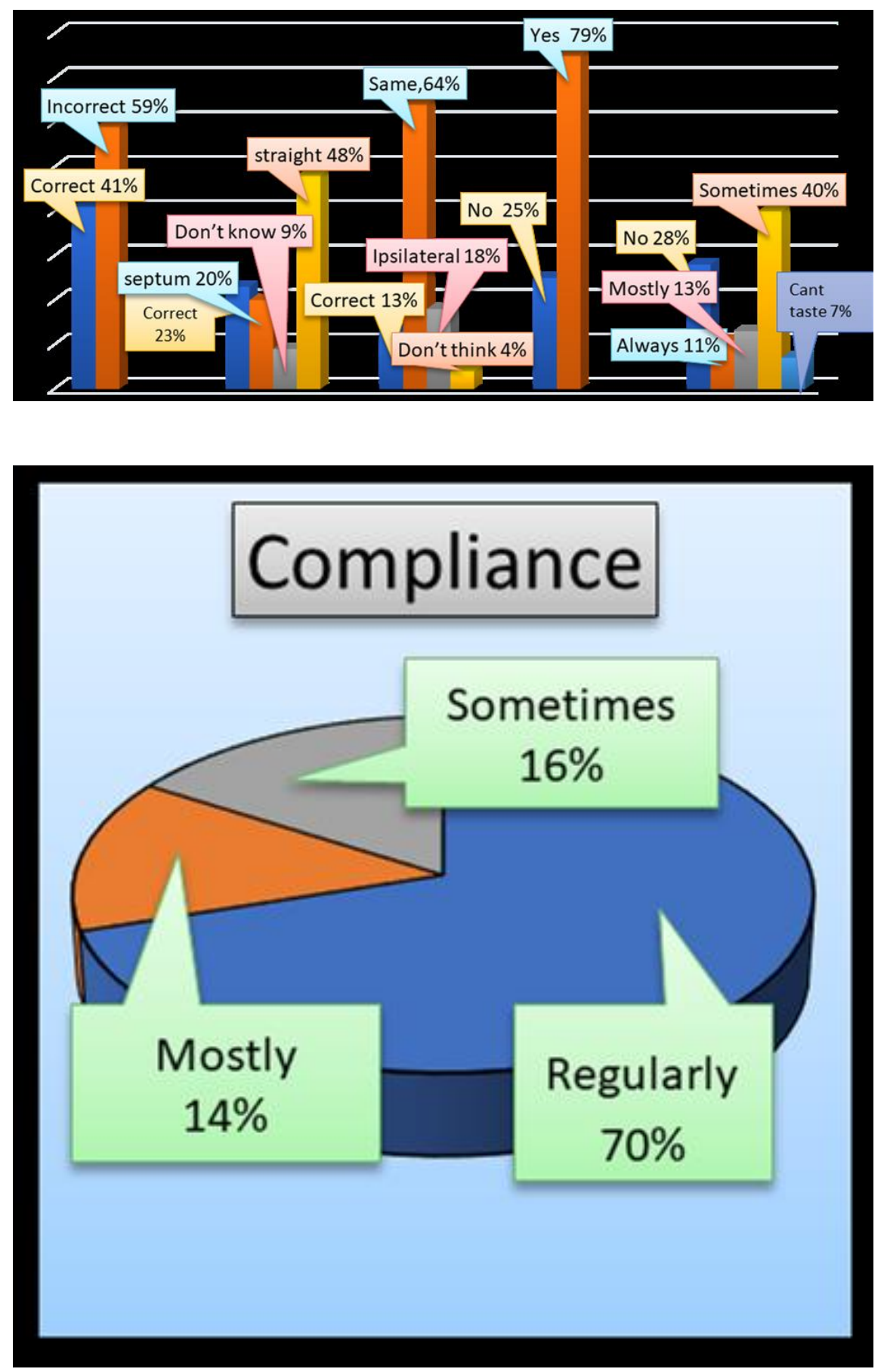